\title{
Hybrid PI-Fuzzy Controller for Brushless DC motor speed control
}

\author{
Dhanya K Panicker ${ }^{1}$, Ms. Remya $\mathrm{Mol}^{2}$ \\ ${ }^{1,2}$ (Electrical and Electronics Engineering,Govt.Engineering College Idukki/M.G.University, India)
}

\begin{abstract}
This paper aims at the design and simulation of hybrid PI-fuzzy control system for the speed control of a brushless dc motor. The performance of the fuzzy logic controller (FLC) is better under transient conditions, while that of the proportional plus integral (PI) controller is superior near the steady-state condition. The combined advantages of these two controllers can be obtained with hybrid PI -fuzzy speed controller. Both the design of the fuzzy controller and its integration with the proportional-integral (PI) controller is to be done. The principle of the proposed control system is to use a PI controller, which performs satisfactorily in most cases, while keeping in the background, a fuzzy controller, which is ready to take over the PI controller when severe perturbations occur. By combining the two controllers, one can get the quick response of the PI controller while eliminating the overshoot possibly associated with it.
\end{abstract}

Keywords: PI, Fuzzy logic, Hybrid Controller, BLDC Motor, Speed Control.

\section{INTRODUCTION}

In recent years, brushless dc (BLDC) machines have gained widespread use in electric drives. These machines are ideal for use in clean, explosive environments such as aeronautics, robotics, electric vehicles, food and chemical industries and dynamic actuation. Using these machines in high-performance drives requires advance and robust control methods. Conventional control techniques require accurate mathematical models describing the dynamics of the system under study. These techniques result in tracking error when the load varies fast and overshoot during transients. In lieu of provisions for robust control design, they also lack consistent performance when changes occur in the system. If advance control strategies are used instead, the system will perform more accurately or robustly. It is therefore, desired to develop a controller that has the ability to adjust its own parameters and even structure online, according to the environment in which it works to yield satisfactory control performance. An interesting alternative that could be investigated is the use of fuzzy logic control (FLC) methods. In the last decade, FLC has attracted considerable attention as a tool for a novel control approach because of the variety of advantages that it offers over the classical control techniques. Unlike other conventional control schemes, FLC is a model-free controller. It does not require an exact mathematical model of the controlled system and therefore, is less sensitive to system parameter changes. In addition, rapidity and robustness are the most profound and interesting properties in comparison to the traditional control methods.

\section{MATHEMATICAL MODEL OF BLDC MOTOR}

BLDC motor can be modeled in the 3-phase abc variables which consist of two parts. One is an electrical part which calculates electromagnetic torque and current of the motor. The other is a mechanical part, which generates revolution of the motor. The electrical part of BLDC motor can be represented in matrix form as follows:

$$
\left[\begin{array}{l}
V_{a n} \\
V_{b n} \\
V_{c n}
\end{array}\right]=\left[\begin{array}{ccc}
R & 0 & 0 \\
0 & R & 0 \\
0 & 0 & R
\end{array}\right]\left[\begin{array}{c}
i_{a} \\
i_{b} \\
i_{c}
\end{array}\right]+\left[\begin{array}{ccc}
L_{\mathrm{a}} & L_{\mathrm{ba}} & L_{\mathrm{ca}} \\
L_{b a} & L_{b} & L_{c b} \\
L_{c a} & L_{c b} & L_{c}
\end{array}\right] \mathrm{d} / \mathrm{dt}\left[\begin{array}{l}
i_{a} \\
i_{b} \\
i_{c}
\end{array}\right]+\left[\begin{array}{l}
e_{a} \\
e_{b} \\
e_{c}
\end{array}\right]
$$

Where $\mathrm{V}_{\mathrm{an}}, \mathrm{V}_{\mathrm{bn}}$ and $\mathrm{V}_{\mathrm{cn}}$ are the phase winding voltages, $\mathrm{R}$ is the resistance per phase of the stator winding, while $i_{a}, i_{b}$ and $i_{c}$ are the phase currents. The back-EMF waveforms $e_{a}, e_{b}, e_{c}$ are functions of angular velocity of the rotor shaft, so

$\mathrm{E}=\mathrm{K}_{\mathrm{e}} \dot{\omega}_{\mathrm{m}}$, where $\mathrm{K}_{\mathrm{e}}$ is the back-emf constant.

If there is no change in rotor reluctance with angle because of a non-salient rotor, and assuming three symmetric phases, the following are obtained.

$\mathrm{L}_{\mathrm{a}}=\mathrm{L}_{\mathrm{b}}=\mathrm{L}_{\mathrm{c}}=\mathrm{L}$
$\mathrm{L}_{\mathrm{ab}}=\mathrm{L}_{\mathrm{ba}}=\mathrm{L}_{\mathrm{ac}}=\mathrm{L}_{\mathrm{ca}}=\mathrm{L}_{\mathrm{bc}}=\mathrm{L}_{\mathrm{cb}}=\mathrm{M}$ 
Substituting equations (2) and (3) in (1) gives the BLDC model as:

$$
\left[\begin{array}{l}
\mathrm{V}_{\mathrm{an}} \\
\mathrm{V}_{\mathrm{bn}} \\
\mathrm{V}_{\mathrm{cn}}
\end{array}\right]=\left[\begin{array}{ccc}
\mathrm{R} & 0 & 0 \\
0 & \mathrm{R} & 0 \\
0 & 0 & \mathrm{R}
\end{array}\right]\left[\begin{array}{l}
i_{a} \\
i_{b} \\
i_{c}
\end{array}\right]+\left[\begin{array}{ccc}
L & M & M \\
M & L & M \\
M & M & L
\end{array}\right] \mathrm{d} / \mathrm{dt}\left[\begin{array}{l}
i_{a} \\
i_{b} \\
i_{c}
\end{array}\right]+\left[\begin{array}{l}
e_{a} \\
e_{b} \\
e_{c}
\end{array}\right]
$$

From equation (4), phase voltage for phase $\mathrm{A}, \mathrm{V}_{\mathrm{an}}$ can be derived as:

$\mathrm{V}_{\mathrm{an}}=\mathrm{R}_{\mathrm{s}} \mathrm{i}_{\mathrm{a}}+\mathrm{Ldi} \mathrm{i}_{\mathrm{a}} / \mathrm{dt}+\mathrm{Md}\left(\mathrm{i}_{\mathrm{b}}+\mathrm{i}_{\mathrm{c}}\right) / \mathrm{dt}+\mathrm{e}_{\mathrm{a}}$

Assume stator currents to be balanced.

$\mathrm{i}_{\mathrm{a}}+\mathrm{i}_{\mathrm{b}}+\mathrm{i}_{\mathrm{c}}=0$

$\mathrm{V}_{\mathrm{an}}=\mathrm{R}_{\mathrm{s}} \mathrm{i}_{\mathrm{a}}+(\mathrm{L}-\mathrm{M}) \mathrm{di}_{\mathrm{a}} / \mathrm{dt}+\mathrm{e}_{\mathrm{a}}$

This is also same for phase $\mathrm{b}$ and $\mathrm{c}$.

$\left[\begin{array}{l}V_{a n} \\ V_{b n} \\ V_{c n}\end{array}\right]=\left[\begin{array}{ccc}R & 0 & 0 \\ 0 & R & 0 \\ 0 & 0 & R\end{array}\right]\left[\begin{array}{l}i_{a} \\ i_{b} \\ i_{c}\end{array}\right]+\mathrm{Ld} / \mathrm{dt}\left[\begin{array}{ccc}L-M & 0 & 0 \\ 0 & L-M & 0 \\ 0 & 0 & L-M\end{array}\right]\left[\begin{array}{l}i_{a} \\ i_{b} \\ i_{c}\end{array}\right]+\left[\begin{array}{l}e_{a} \\ e_{b} \\ e_{c}\end{array}\right]$

Neutral voltages are referred to the zero reference potential at midpoint of dc-link (0). So phase voltage can be expressed as:

$\mathrm{V}_{\mathrm{an}}=\mathrm{V}_{\mathrm{ao}}-\mathrm{V}_{\mathrm{no}}$

$\mathrm{V}_{\mathrm{bn}}=\mathrm{V}_{\mathrm{bo}}-\mathrm{V}_{\mathrm{no}}$

$\mathrm{V}_{\mathrm{cn}}=\mathrm{V}_{\mathrm{co}}-\mathrm{V}_{\mathrm{n} 0}$

where $\mathrm{V}_{\mathrm{ao}}, \mathrm{V}_{\mathrm{bo}}, \mathrm{V}_{\mathrm{co}}$ and $\mathrm{V}_{\mathrm{no}}$ are the output phase voltages from the inverter and the potential of the star point referred to the neutral respectively. In order to avoid unbalance in applied voltages, a balanced star connected three phase winding is considered.

The developed electromagnetic torque can be expressed as:

$\mathrm{T}_{\mathrm{e}}=\mathrm{Jd} \omega / \mathrm{dt}+\mathrm{B} \omega+\mathrm{T}_{1}$

where $\mathbf{J}$ is moment of inertia in $\mathrm{kg}-\mathrm{m}^{2}$, B is frictional coefficient in $\mathrm{N}-\mathrm{ms} / \mathrm{rad}, \mathrm{T}_{1}$ is the load torque in $\mathrm{Nm}$. But the electromagnetic torque for this 3-phase BLDC motor is dependent on the current, speed and backEMF waveforms, so the instantaneous electromagnetic torque can be represented as:

$\mathrm{T}_{\mathrm{e}}=\left(\mathrm{e}_{\mathrm{a}} \mathrm{i}_{\mathrm{a}}+\mathrm{e}_{\mathrm{b}} \mathrm{i}_{\mathrm{b}}+\mathrm{e}_{\mathrm{c}} \mathrm{i}_{\mathrm{c}}\right) / \omega$.

The derivative of electrical rotor position $\theta_{r}$ is expressed as:

$$
\frac{d \theta_{r}}{d t}=\frac{P}{2} \omega_{r}
$$

where $\mathrm{P}$ is the number of poles, $\omega_{\mathrm{r}}$ is the rotor speed in mechanical $\mathrm{rad} / \mathrm{sec}$ and $\theta_{\mathrm{r}}$ is the electrical rotor position in electrical radian.

\section{SPEED CONTROLLER}

Many drive systems today employ a conventional controller such as a PI-type controller. This method works well, but only under a specific set of known system parameters and load conditions. However, deviations of the system parameters or load conditions from the known values cause the performance of the closed-loop system to deteriorate, resulting in larger overshoot, larger rise time, longer settling times and, possibly, an unstable system. It should be noted that the system parameters such as the system inertia and damping ratio might vary over a wide range due to changes in load conditions. Generally, a PI speed controller could be tuned to a certain degree in order to obtain a desired performance under a specific set of operating conditions. Less than ideal performance is then observed when these operating conditions vary. Thus, there is a need for other types of controllers, which can account for nonlinearities and are somewhat adaptable to varying conditions in real time. Other methods are now being employed, such as fuzzy logic, in order to achieve a desired performance level. 


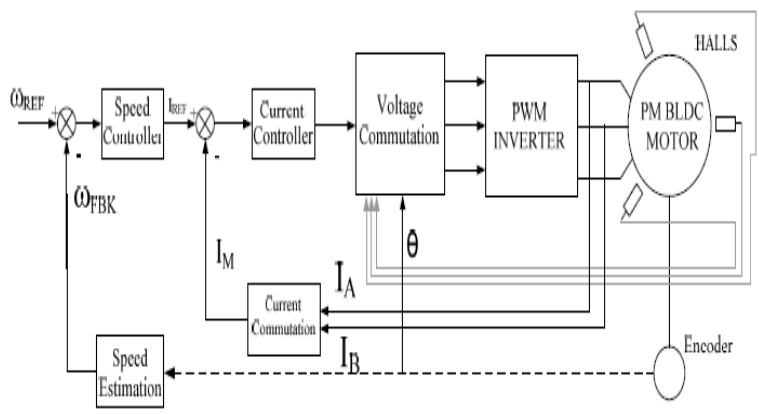

Fig. 1 Closed loop speed control of BLDC motor

The model of speed controller has been realized using the Simulink toolbox of the MATLAB software. The main function of speed controller block is to provide a reference torque which in turn is converted to reference current and is fed to current reference generator. The output of the speed controller is limited to a proper value in accordance with the motor rating to generate the reference torque. The speed controllers realized in this project are proportional integral (PI) controller, fuzzy logic (FLC) controller and hybrid PI-Fuzzy controller.

\section{A. PI Controller}

The proportional plus integral (PI) controller is widely used for industrial applications. The input to the PI controller is the speed error (E), while the output of the PI controller is used as the input of reference current block.

\section{B. Fuzzy Logic Controller}

Fuzzy logic control (FLC) is a rule based controller. It is a control algorithm based on a linguistic control strategy which tries to account the human's knowledge about how to control a system without requiring a mathematical model. The approach of the basic structure of the fuzzy logic controller system is illustrated in Fig.2 .

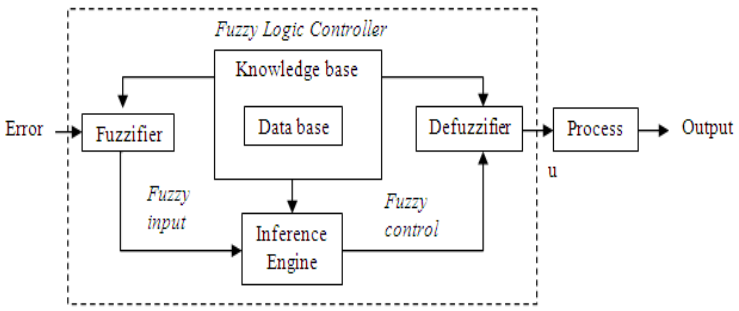

Fig. 2 Basic structure of Fuzzy Logic controller

Fuzzy logic uses linguistic variables instead of numerical variables. The process of converting a numerical variable (real number or crisp variables) into a linguistic variable (fuzzy number) is called Fuzzification. Here the inputs for Fuzzy Logic controller are the speed error (E) and change in speed error (CE). Speed error is calculated with comparison between reference speed and the actual speed. The fuzzy logic controller is used to produce an adaptive control so that the motor speed can accurately track the reference speed. The reverse of Fuzzification is called Defuzzification. The use of Fuzzy Logic Controller (FLC) produces required output in a linguistic variable (fuzzy number). According to real world requirements, the linguistic variables have to be transformed to crisp output.

The membership function is a graphical representation of the magnitude of participation of each input. There are different membership functions associated with each input and output response. Here the trapezoidal membership functions are used for input and output variables. The number of membership functions determines the quality of control which can be achieved using fuzzy controller. As the number of membership function increases, the quality of control improves. As the number of linguistic variables increases, the computational time and required memory increases. Therefore, a compromise between the quality of control and computational time is needed to choose the number of linguistic variables. The most common shape of membership functions is triangular, although trapezoidal and bell curves are also used, but the shape is generally less important than the number of curves and their placement. 
The processing stage is based on a collection of logic rules in the form of IF-THEN statements, where the IF part is called the "antecedent" and the THEN part is called the "consequent". The knowledge base comprises knowledge of the application domain and the attendant control goals. It consists of a data "base" and a linguistic (fuzzy) control rule base. The data base provides necessary definitions, which are used to define linguistic control rules and fuzzy data manipulation in an FLC. The rule base characterizes the control goals and control policy of the domain experts by means of a set of linguistic control rules. Decision making logic is the kernel of an FLC.

The most important things in fuzzy logic control system designs are the process design of membership functions for input, outputs and the process design of fuzzy if-then rule knowledge base. Fig 3 shows the membership function of speed error (E), change in speed error (CE) and figue.4 shows the membership function of output variable. In practice, one or two types of membership functions are

\begin{tabular}{|l|l|l|l|l|l|l|l|}
\hline ECE & NB & NM & NS & Z & PS & PM & PB \\
\hline NB & PB & PB & PM & PM & PS & PS & NS \\
\hline NM & PB & PM & PM & PS & PS & Z & NS \\
\hline NS & PM & PM & PS & Z & Z & NS & NS \\
\hline$Z$ & PM & PS & PS & Z & NS & NS & NM \\
\hline PS & PS & PS & Z & NS & NS & NM & NM \\
\hline PM & PS & Z & NS & NS & NM & NM & NB \\
PB & Z & NS & NS & NM & NM & PB & NB \\
\hline
\end{tabular}

Table. 1 Rule base of Fuzzy logic controller

Enough to solve most of the problems. The next step is to define the control rules. There are no specific methods to design the fuzzy logic rules. However, the results from PI controller give an opportunity and guidance for rule justification. Therefore after thorough series of analysis, the total 49 rules have been justified as shown in Table 1.

The membership function is divided into seven sets: NB: Negative Big, NM: Negative Medium, NS: Negative Small, Z: Zero, PS: Positive Small, PM: Positive Medium, PB: Positive Big.

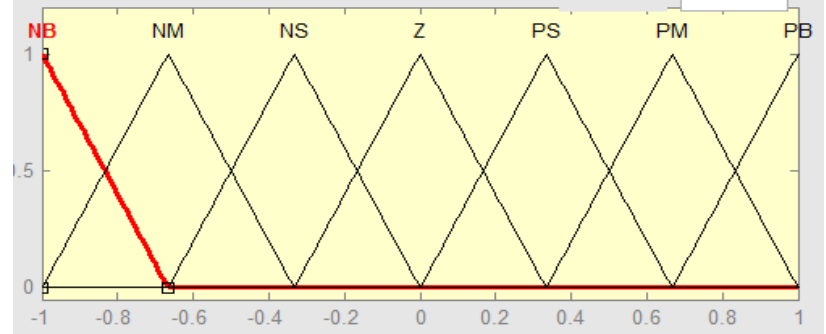

Fig.3 Membership function plots, error and change in error

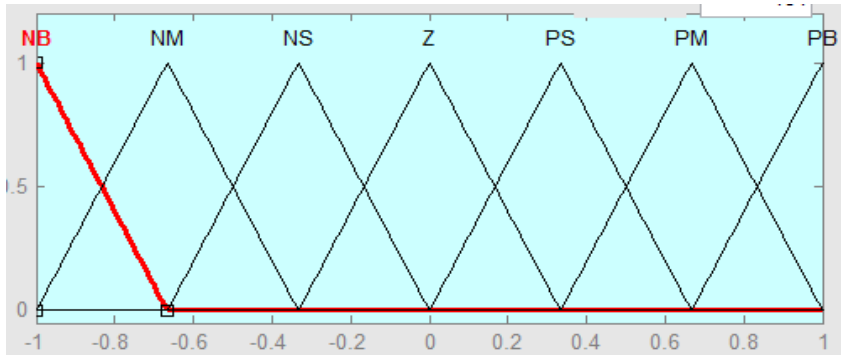

Fig 4. Membership function plots, output variable

\section{Hybrid PI-Fuzzy Controller}

The objective of the hybrid controller is to utilize the best attributes of the PI and fuzzy logic controllers to provide a controller which will produce better response than either the PI or the fuzzy controller. There are two major differences between the tracking ability of the conventional PI controller and the fuzzy logic controller. Both the PI and fuzzy controller produce reasonably good tracking for steady-state or slowly varying operating conditions. However, when there is a step change in any of the operating conditions, such as may occur in the set point or load, the PI controller tends to exhibit some overshoot or oscillations. The fuzzy controller reduces both the overshoot and extent of oscillations under the same operating conditions. Although the fuzzy controller has a slower response by itself, it reduces both the overshoot and extent of 
oscillations under the same operating conditions. The desire is that, by combining the two controllers, one can get the quick response of the PI controller while eliminating the overshoot possibly associated with it.

\section{Switching Control Strategy}

The switching between the two controllers needs a reliable basis for determining which controller would be more effective. The answer could be derived by looking at the advantages of each controller. Both controllers yield good responses to steady-state or slowly changing conditions. To take advantage of the rapid response of the PI controller, one needs to keep the system responding under the PI controller for a majority of the time, and use the fuzzy controller only when the system behavior is oscillatory or tends to overshoot. Thus, after designing the best stand-alone PI and fuzzy controllers, one needs to develop a mechanism for switching from the PI to the fuzzy controllers, based on the following two conditions:

1) Switch when oscillations are detected;

2) Switch when overshoot is detected.

The switching strategy is then simply based on the following conditions:

IF the system has an oscillatory behavior

THEN fuzzy controller is activated,

Otherwise PI controller is operated.

IF the system has an overshoot

THEN fuzzy controller is activated,

Otherwise PI controller is operated.

The system under study is considered as having an overshoot when the error is zero and the rate of change in error is any other value than zero. The system is considered oscillatory when the sum of the absolute values of the error taken over time does not equal the absolute values of the sum of the error over the same period of time. Since the system is expected to overshoot during oscillatory behavior, the only switching criterion that needs to be considered is overshoot. However, in practice, it is more convenient to directly implement the control signal according to the control actions delivered by the controller. Consequently, the fuzzy controller can be designed so that normal behavior (no oscillations or overshoot) results in a null fuzzy action. Accordingly, the switching between the two controllers reduces to using PI if the fuzzy has null value; otherwise, the fuzzy output is used. In particular, the fuzzy controller can be designed so that a normal behavior

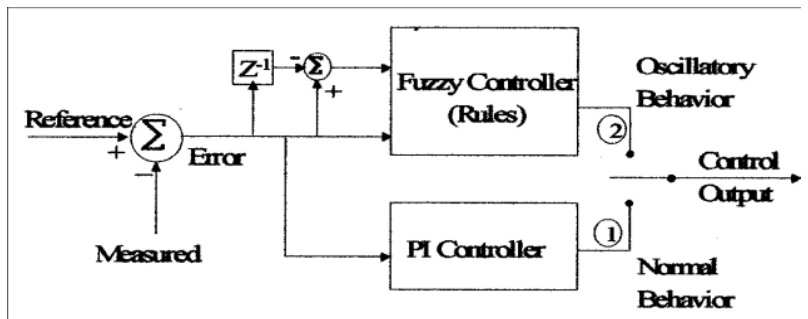

Fig.5 Structure of switching strategy results in a null fuzzy action.

\section{Simulation And Results}

\section{A. Body Block Of Bldc Motor}

Fig. 6 shows the simulation model of the electrical block of BLDC motor

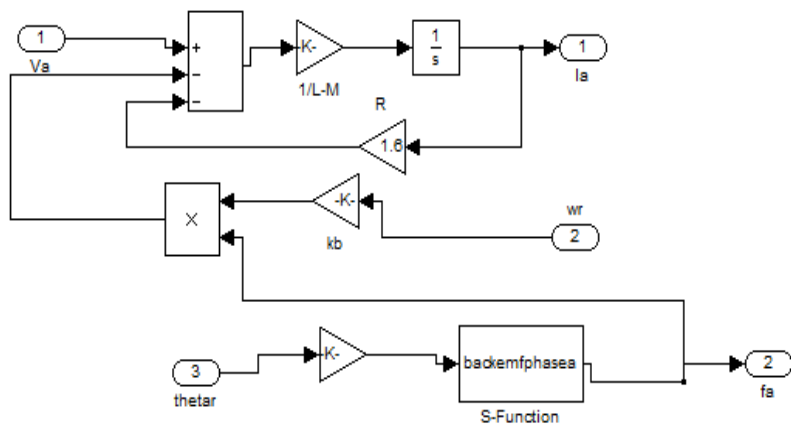

Fig. 6 Electrical block of phase a 
Fig.7 and Fig.8 shows the simulation models for building mechanical block of BLDC motor

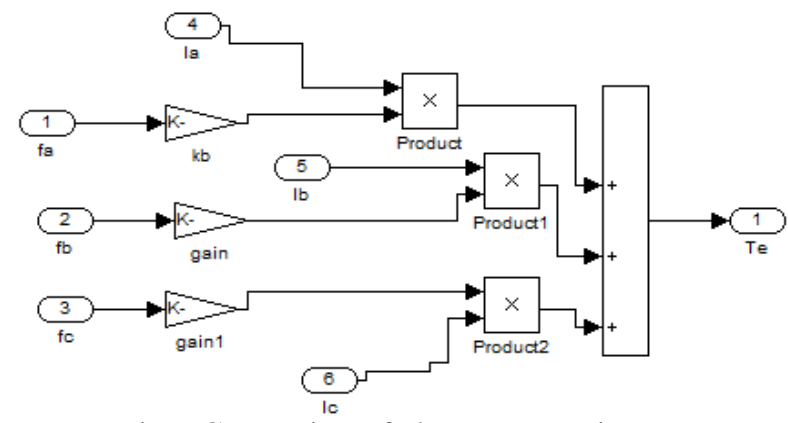

Fig.7 Generation of electromagnetic torque

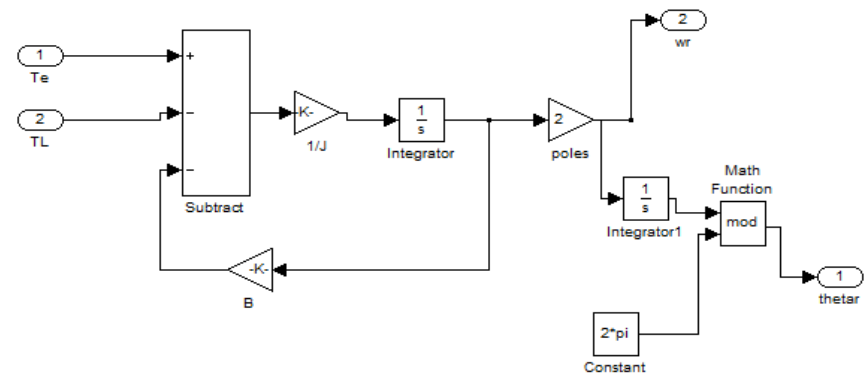

Fig.8 Simulink model for the generation of rotor speed

\section{Commutation Logic Block}

The reliable commutation of inverter for BLDC motor control system is controlled by the rotor position signal. The function of this block is to decide the switching order of six power tubes according to position of the magnetic poles. The position signal of magnetic poles acts as inputs, and the switching logic signals of six power tubes act as outputs, as shown in Fig.9 and 10

\section{Hall Sensor Signal Generation}

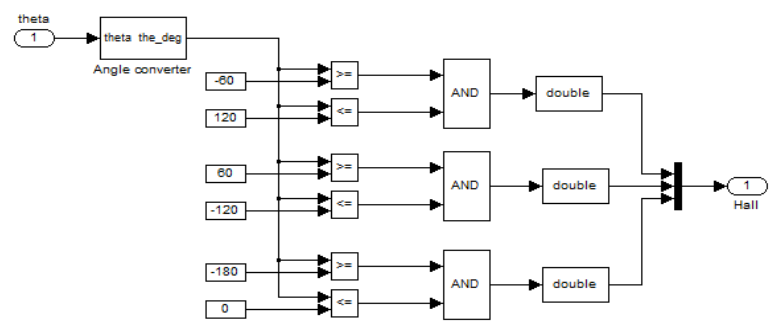

Fig.9 Generation of Hall sensor signals

D. Gate Signal Generation

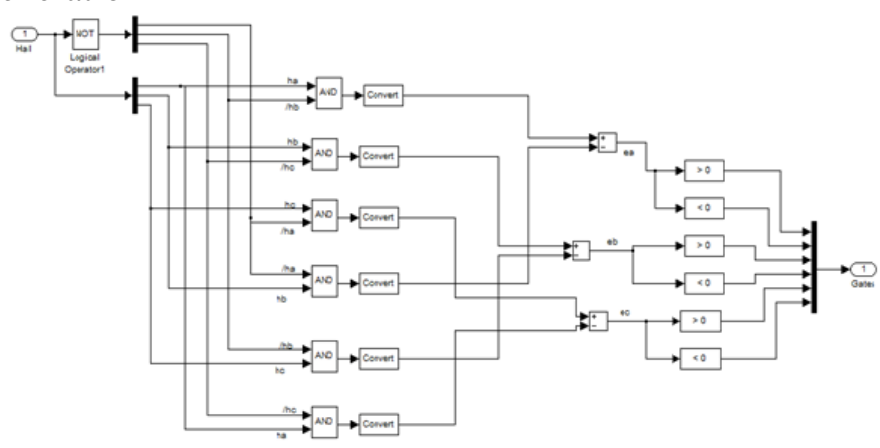

Fig.10 Generation of gate signals 


\section{E. Voltage Source Inverter}

The voltage inverter block uses three-phase full-bridge inverter. The model of six power tubes can be built by using switching devices MOSFET in Simulink/SimPowerSystems Toolbox, as shown in Fig.11

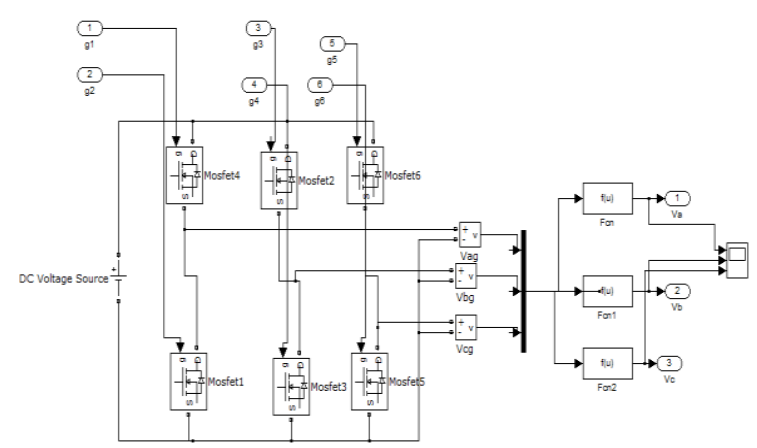

Fig.11 Voltage source inverter

\section{F. Open Loop Bldc}

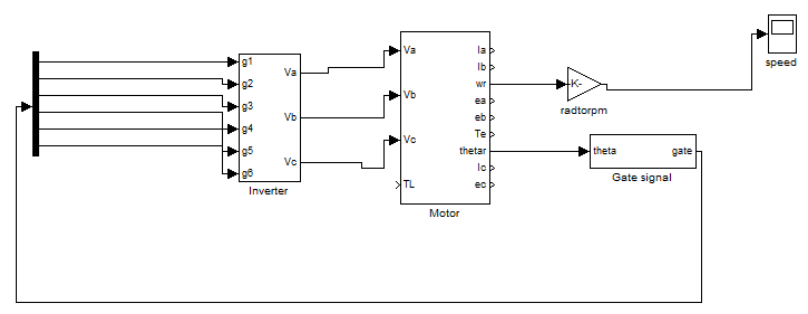

Fig.12 Simulink model of open loop BLDC motor

Fig.13 shows the generated hall signals

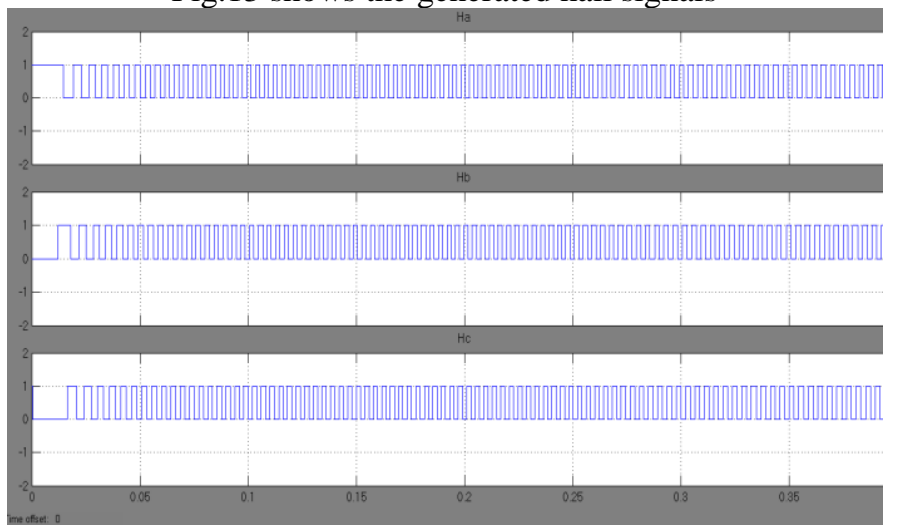

Fig.13 Hall sensor signals

Fig.14 shows the voltage source inverter output.
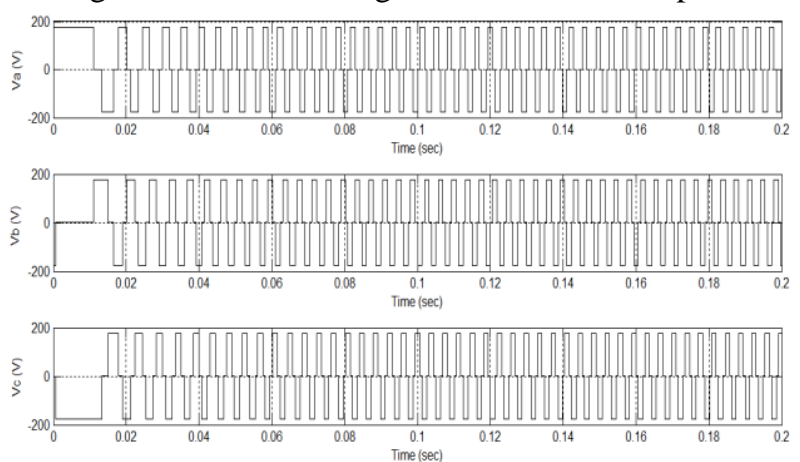

Fig.14 Voltage source inverter output 

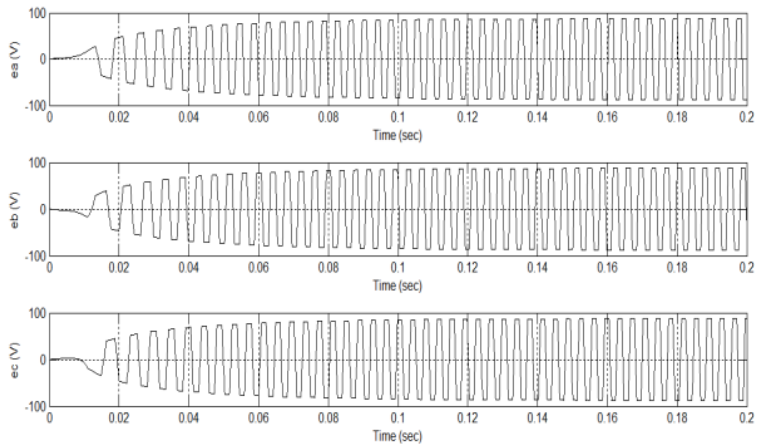

Fig.15 Back emf waveforms

\section{G. Open Loop Speed Response}

Fig.16 shows the open loop speed response of BLDC motor.

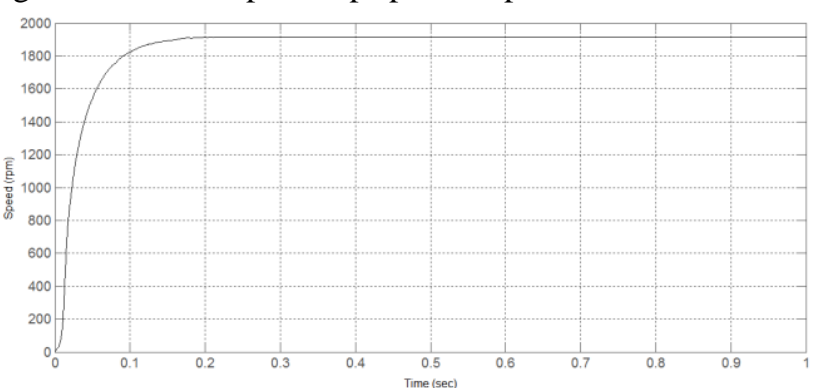

Fig.16 Open loop speed response of BLDC motor

\section{H. . Current Controller}

\section{H. A. Current Reference Block}

The action of the current reference block is to produce three-phase reference currents, $\mathrm{i}_{\mathrm{ar}}, \mathrm{i}_{\mathrm{br}}, \mathrm{i}_{\mathrm{cr}}$ depending on the signal of current amplitude, Is, and the position signal, Then the reference currents are directly given to the current hysteresis controller block. Table 2 shows corresponding relation between the rotor position and the three-phase reference current

\begin{tabular}{|c|c|c|c|}
\hline theta & $\mathrm{i}_{u r}$ & $\mathrm{i}_{\mathrm{ber}}$ & $\mathrm{i}_{\mathrm{cc}}$ \\
\hline $0 \sim \pi / 3$ & Is & -Is & 0 \\
\hline$\pi / 3 \sim 2 \pi / 3$ & Is & 0 & -Is \\
\hline $2 \pi / 3 \sim \pi$ & 0 & Is & -Is \\
\hline$\pi \sim 4 \pi / 3$ & -Is & Is & 0 \\
\hline $4 \pi / 3 \sim 5 \pi / 3$ & -Is & 0 & Is \\
\hline $5 \pi / 3 \sim 2 \pi$ & 0 & -Is & Is \\
\hline
\end{tabular}

Table. 2 Relationship between reference current and rotor position

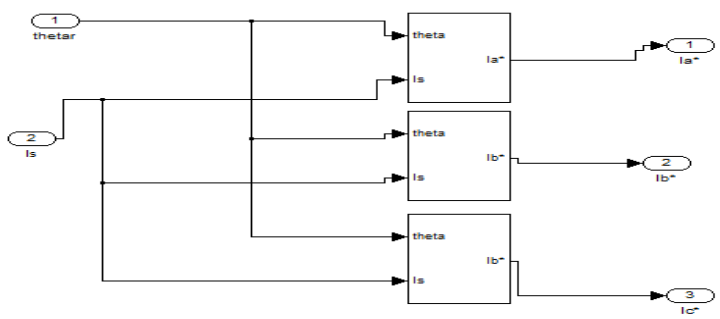

Fig.17 Reference current generator

\section{H.B. Hysteresis Current Controller Block}

Current hysteresis controller block is to achieve hysteresis current control, in which input signals are three phase reference currents and practical currents, and output signals will act as the control signals of inverter. When the practical current is greater than the reference current and the error is greater than the ring width of hysteresis comparator, the corresponding phase will be conducted forward and turn off reversely. 
Conversely, it will be conducted reversely and turn off forward. When selecting proper hysteresis ring width, the practical current will track the reference current continuously. By this means the current closed-loop control can be achieved.

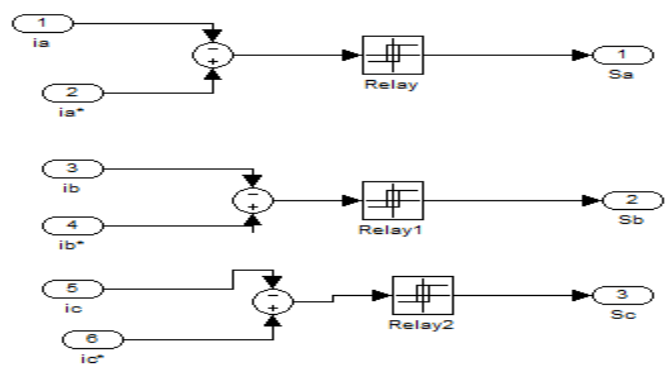

Fig.18 Hysteresis current controller

\section{Closed Loop Control Of Bldc Motor Using Pi-Controller}

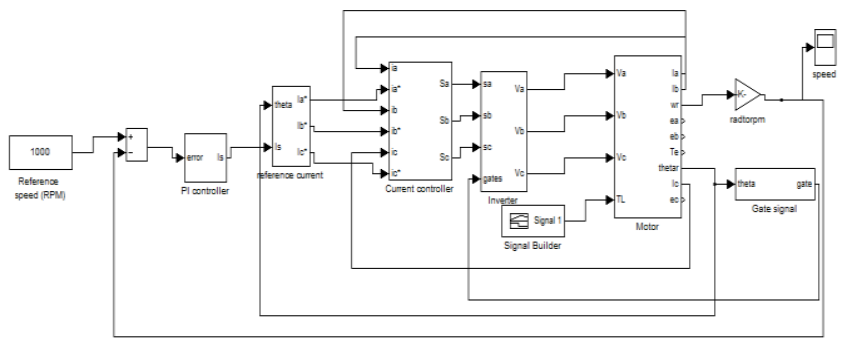

Fig.19 Simulink block of closed loop speed control using PI controller

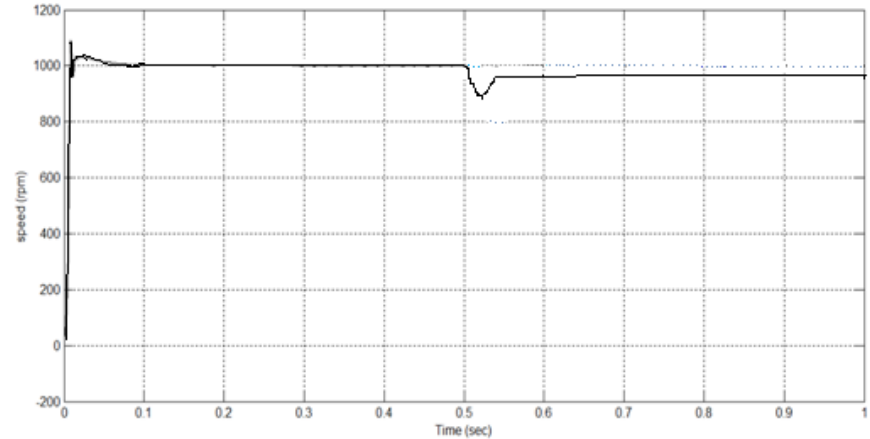

Fig.20 Speed response using PI controller in closed loop

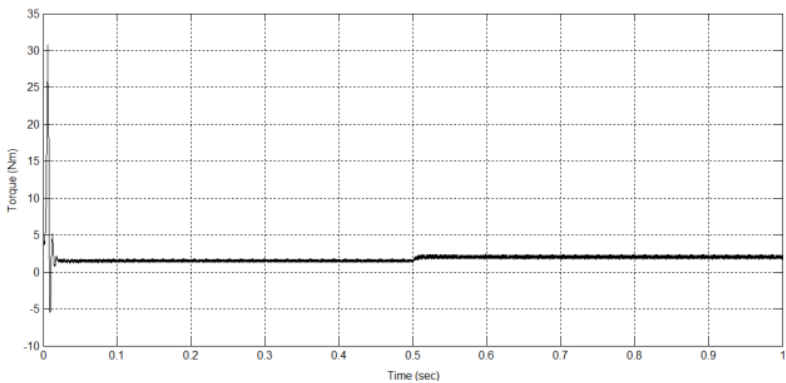

Fig.21 Electromagnetic Torque response using PI controller in closed loop

\section{Fuzzy Logic Controller}

Here the inputs for Fuzzy Logic controller are the speed error (E) and change of speed error (CE). Speed error is calculated with comparison between reference speed and the actual speed. 


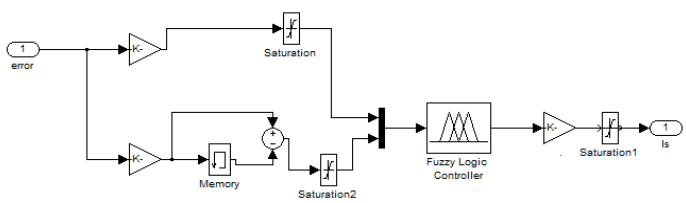

Fig.22 Simulink model of Fuzzy logic controller

Fig.23 shows the speed response of BLDC motor while using fuzzy logic controller as the speed controller.

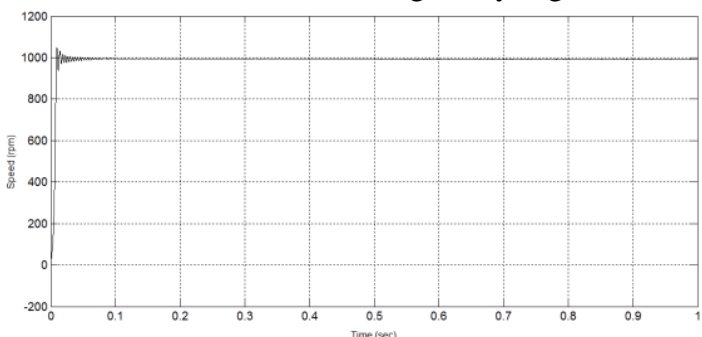

Fig.23 Speed response using fuzzy logic controller

\section{Hybrid Pi- Fuzzy Controller}

The objective of the hybrid controller is to utilize best attributes of the PI controller and fuzzy controller to provide a controller which will produce better response than either PI or fuzzy controller. The superiority of both fuzzy and PI controller are integrated together by using a switch as shown in Fig.24. The speed error and simulation time control the switch such that it will be switched to fuzzy controller when the speed error is large and vice versa to PI controller when the speed error is small with appropriate time.

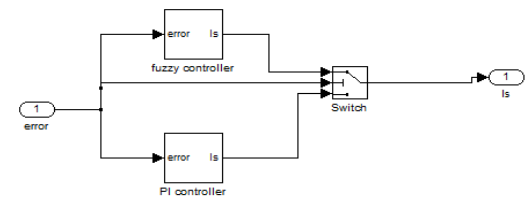

Fig.24 Simulink model of Hybrid PI- Fuzzy controller

Fig.25 shows the speed response of BLDC motor while using Hybrid PI - fuzzy controller as the speed controller

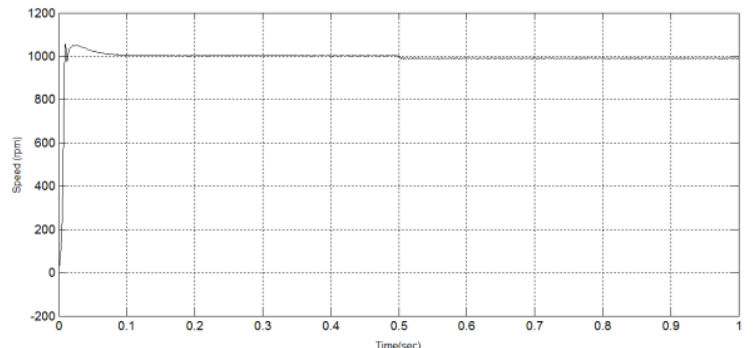

Fig.25 Speed response using hybrid PI-fuzzy controller

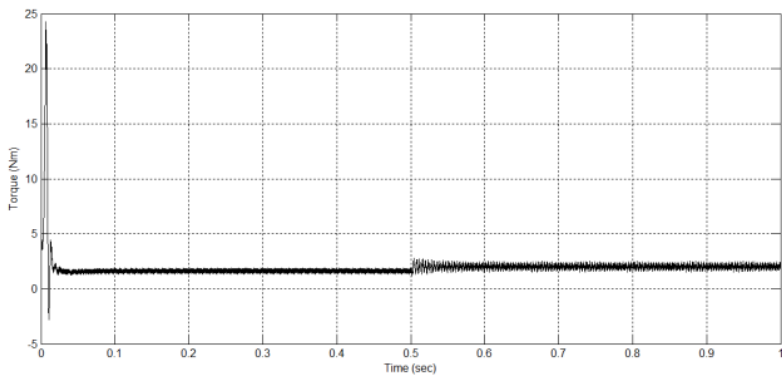

Fig.26 Electromagnetic Torque response using hybrid PI-fuzzy controller 


\section{COMPARISON BETWEEN SPEED CONTROLLERS}

When a step change at 0.5 was applied the PI controller failed to track the reference speed of 1000rpm which was well tracked by the fuzzy controller. During steady state conditions, the settling time of fuzzy controller was found to be more when compared to PI controller. In hybrid PI Fuzzy controller this is compensated by the combined action of PI and Fuzzy controller.

\section{CONCLUSION}

This paper presented the design of a hybrid PI-fuzzy control system for the speed control of a brushless dc motor The performance of the fuzzy logic controller is better under transient conditions, while that of the proportional plus integral controller is superior near the steady state condition. The combined advantages of these two controllers can be obtained with hybrid PI-fuzzy speed controller. Mathematical model of the BLDC motor is studied. Based on this, the modeling and simulation of the proposed control system is done. The performance of the system using PI controller, fuzzy logic controller and hybrid PI- fuzzy controller are compared. It is shown through extensive simulation that the performance of the Hybrid PI- Fuzzy controller is better than using PI controller and fuzzy controller alone for the speed control of BLDC motor.

\section{REFERENCES}

[1] Ahmed R., Daniel R. and David M.D. "Experimental Verification of a Hybrid Fuzzy Control Strategy for a High-Performance Brushless DC Drive system”. IEEE Transactions on Industry Applications, Vol.37, No.2, March-April 2001, pp.503-512

[2] Tan C.S., Baharuddin I. "Study of Fuzzy and PI controller for permanent magnet brushless dc motor drive". Proceedings of International Power Engineering and Optimization Conference, June 23-24, 2010, pp.517- 521

[3] Sayed H.S., Khouly F.M., "Fuzzy logic based control of a permanent magnet brushless de motor drive" AIAA, No.78-1291, 1978.

[4] Dumitru D., Chemin B.,"A PI-Fuzzy Controller Designated For Industrial Motor Control Application”. AIAA, 1990, pp.949-954

[5] Arnulfo R.M., Raul G.R., " PI Fuzzy Gain- Scheduling Speed Control at Startup of a Gas-Turbine Power Plant” IEEE Transactions on energy conversion, vol.26, NO.1, March 2011, pp.467-473 